\title{
An Interactive Mobile Lecturing Tool for Aggregating Learning Resources
}

\author{
Olutayo Boyinbode, Dick Ng’ambi, Antoine Bagula \\ Department of Computer Science, Centre for Educational Technology, University of Cape \\ Town, South Africa
}

\begin{abstract}
Vodcasts are increasingly becoming popular in higher education as a means of enhancing learning especially for part time students who are separated by distance from their tutor. In this paper we propose a tool, MOBILect, that enables students to comment on lecture vodcasts using mobile devices, and aggregated comments become an educational resource. The vodcasts are generated through YouTube. The tool was evaluated at the Bindura University of Science Education Zimbabwe. The paper reports on the architecture of the MOBILect, its framework for student-vodcast interaction, and evaluation results. The paper concludes that the MOBILect has potential for use as a supplement to the traditional face-to-face lectures especially in scenarios where students are separated by distance.
\end{abstract}

\section{Introduction}

Most institutions of higher education are using podcasting or vodcasting as a way of widening access to e-learning to improve learning among their students [5]. A podcast is a collection of digital media files (audio) distributed over the internet using Really Simple Syndication (RSS) technology or Atom feeds ${ }^{1}$. A vodcast is a video podcast.

Most institutions of higher education have a productive podcasting or vodcasting program. Due to the advances in mobile and wireless technologies, usage of smart phones, iPhones, iPads and tablets have become prominent in mobile learning [12]. Students can watch lecture vodcast on their mobile devices while on campus where most often they have free access to internet and can also download it and move with it to off campus. Students move from campus to off campus with lecture vodcasts on their mobile devices and collaborate with other students anywhere and anytime. Podcast or vodcast has emerged as a tool for mobile learning where students download lecture vodcast to their mobile devices and learn on the move [2]. Lecture vodcast or podcast and face-

1. http:// validator.w3.org/feed/docs/rss2.html to-face lecture have one way communication (unidirectional) though podcasts still have the advantage that learners can re-listen to lectures after face-to-face lecture and take down notes though this interaction is limited to actively engage students in deep learning. Deep learning is a form of learning where learners extract meaning and understanding from lecture materials [11]. Students cannot interact by asking questions or get access to other peer's ideas which are critical to foster deep learning. This paper presents an interactive mobile lecturing tool "MOBILect" that allows students to interact with lecture vodcasts on their mobile devices in a bidirectional interaction overcoming the limitation of unidirectional interaction inherent in lecture podcast or vodcast. Section 2 presents the use of podcast in face-to-face learning. Section 3 describes the podcasting or vodcasting technology. Section 4 describes an interactive mobile lecturing tool" MOBILect". Section 5 describes the evaluation result obtained from the Bindura University of Science Education Zimbabwe. Section 6 presents the conclusion.

\section{Face-to-Face Lecture and Podcasting}

Face-to-face lectures are not a particularly effective means for enhancing student centred learning $[5,8,3,4,10]$. Teachers use face-to-face lecture to present content and information to learners, the lecture is usually unidirectional and does not engage students to interact in learning. The general passive role of students in most faceto-face lectures emphases the need for more students centred learning strategies [8]. There has not been significant improvement in the face-toface learning through the years; the evolution of podcasting and vodcasting technology has opened up many possibilities [8]. Podcasting is the process of making files accessible to listeners, via the internet or a computer network from which they can be downloaded onto an iPod or other player. In podcasting technology users can subscribe to a podcast feed; podcasts are automatically pushed to the RSS reader or aggregator (e.g. iTunes, iTuneU). Podcasting has seen significant growth in higher education in recent times by its ability to support mobile learning and enhance student's learning experience [8, 9]. Copley [3] notes that a number of 
universities have commenced and implemented the use of podcasts to deliver supplementary lecture materials for students. He further observes that the most common use of podcasts in the universities is for the distribution of lecture recordings to enhance student reviewing and revision. Podcasting technology facilitates a mobile learning environment where learners can download podcasts to their mobile devices and move about with it and learn when convenient. Though podcast lecture is also unidirectional as the face-to-face lecture (this is shown in figure 1) podcasts still have the advantage that learners can re-listen to lectures after face-to-face lecture and take down notes though this interaction is limited to engage students in deep learning. The similarities of face-to-face lecture and podcast lecture are shown in figure 1.

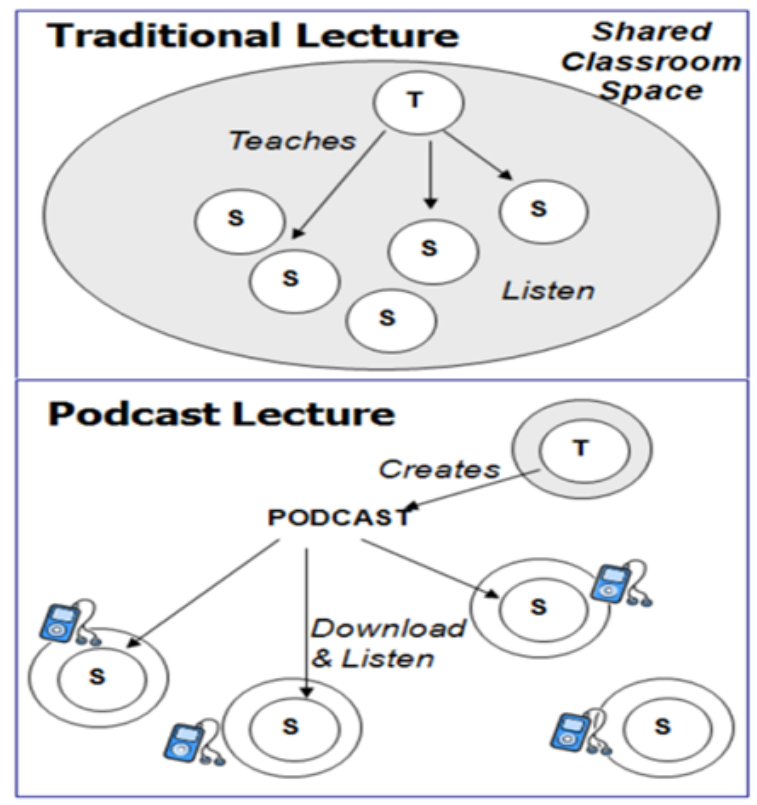

Figure 1. Face-to-face lecture versus
Podcast Lecture Source from [7]

\section{Podcasting and Vodcasting Technology}

Podcasting or vodcasting has been adopted and adapted in higher education because of their flexibility and easy access to lecture materials by students [6]. A podcast is an audio file while vodcast is a video file that is distributed over the internet for playback on students' personal computers or mobile devices such as MP3 players or Apple's iPod. Podcasting and vodcasting refers to the distribution of media files by RSS (Really Simple Syndication) technology, through which new files are automatically downloaded to the subscriber [3].

Podcast emerged in 2004 and has its name derived from Apple's iPod, it has become a popular technology for the distribution of audio and video, entertainment and news over the internet. Podcasting or vodcasting enables students to access learning resources whenever they desire, at home, on campus or while walking to campus or work, at any time that is convenient for them. Hence, they provide students learning resource anywhere and anytime [6, 7].

\section{Mobile Lecturing}

Mobile lecturing aims to achieve mobile learning by enabling students to interact with lecture vodcasts on their mobile devices while on the move [2]: An interactive mobile lecturing tool "MOBILect" is developed to allow students to access lecture vodcasts on their mobile devices.

\subsection{An Interactive Mobile Lecturing Model}

Based on Anderson educational interactions [1]; an interactive mobile lecturing model is proposed (see figure 2). We illustrate the possible interactions with learning content by students and teacher using the interactive mobile lecturing model. This model aggregates learning contents which are made available to students. In this model students and teachers interacts using their mobile devices. See the interactions below based on Anderson's educational interactions [1]; Student-to-Student, Student-to-Teacher, Student-to-Content, Teacherto-Content interactions.

\section{Teacher- to- Content Interaction}

$\mathrm{T}=>\mathrm{C}$

Teacher creates Content C

\section{Student -to- Content Interaction}

$\mathrm{S} 1=>\mathrm{C}=\mathrm{A}$

Student 1 (S1) interacts with Content C and creates Content A

$\mathrm{S} 2=>\mathrm{C}=\mathrm{B}$

Student 2 (S2) interacts with Content C and creates Content B

$\mathrm{S} 3=>\mathrm{C}=\mathrm{D}$

Student 3 (S3) interacts with Content C and creates Content D

\section{Student- to- Student Interaction}

$\mathrm{S} 1=>\mathrm{S} 2 ; \mathrm{B}=>\mathrm{E}$

Student 1 (S1) interacts with Content B (created by S2) and creates Content E 


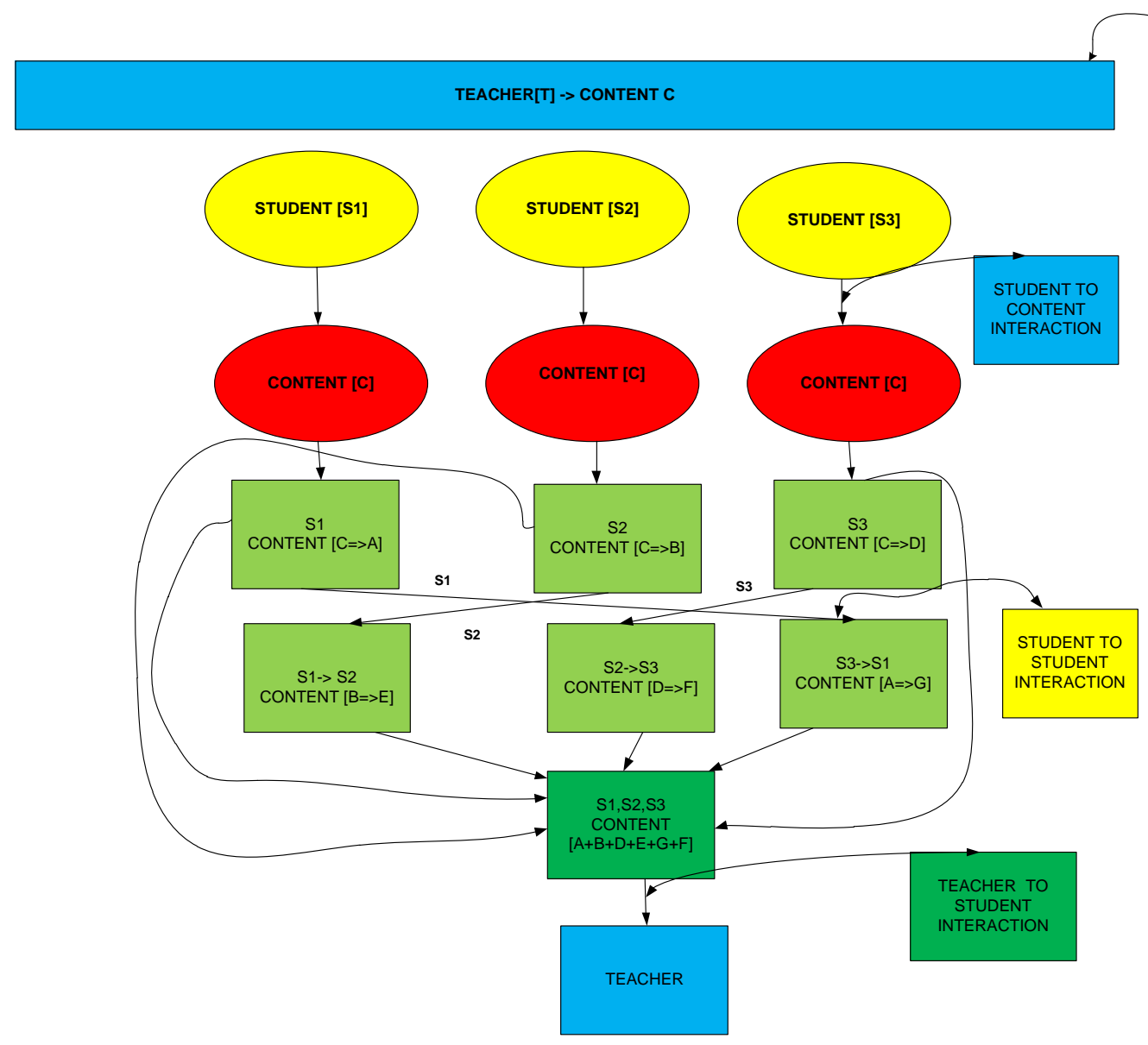

Figure 2. An Interactive Mobile Lecturing Model

$\mathrm{S} 2=>\mathrm{S} 3 ; \mathrm{D}=>\mathrm{F}$

Student 2 (S2) interacts with Content D (created by S3) and creates Content F

$\mathrm{S} 3=>\mathrm{S} 1 ; \mathrm{A}=>\mathrm{G}$

Student 3 (S3) interacts with Content A (created by S1) and creates Content G

\section{Teacher- to- Student Interaction}

$\mathrm{T}=>\mathrm{A}, \mathrm{B}, \mathrm{D}, \mathrm{E}, \mathrm{F}, \mathrm{G}$

Teacher T interacts with Contents A, B, D, E, F, G to correct any misconceptions and give feedback to students

\subsection{YouTube}

YouTube is a video-sharing application that allows various files to be uploaded to YouTube servers when online. YouTube allows users to tag videos, post comments in a threaded-discussion format and search for content with keyword or category $^{2}$

YouTube is a website designed to allow users from all over the world to post video created from any source. With YouTube you can either watch or upload video. To upload a video you need to create an account. The account creation process is very simple and usually linked to an existing account like gmail.com. The user friendly software of YouTube enables editing various videos to your taste. The benefit of using YouTube when compared to other video sites is the content availability. YouTube is a very simple website to use with the videos ready to watch at the click of a button. YouTube has created the ability to skip ahead to the part of the video you would like to see, without having to endure the wait of loading the first or last part of a video. Besides the easy to watch video technology, the easy to upload process creates many benefits when compared to other sites $^{2}$. YouTube broadcasts to an audience of 
millions. YouTube is available in nearly every country in the world on any computer that has internet access, and is visited each day by millions of people. Getting a message out or broadcasting yourself to audience of millions is as simple as creating the video and then utilising YouTube's uploading. YouTube enables users to view and engage with videos, though most of the content on YouTube lacks educational goal (authentic contents). Lecture vodcasts (educational contents) are uploaded into YouTube. Interactive mobile lectures (MOBILect) accesses recorded lectures in YouTube uploaded with \#uct tag (see figure 4). These lecture vodcasts are interacted with through MOBILect. Figure 3 shows how to select the file to be uploaded to You Tube. Figure 4 shows the details to include in the file upload for the file to be made available to MOBILect. The details are the title of the video, the description of the video, the \#uct tag for the video etc.

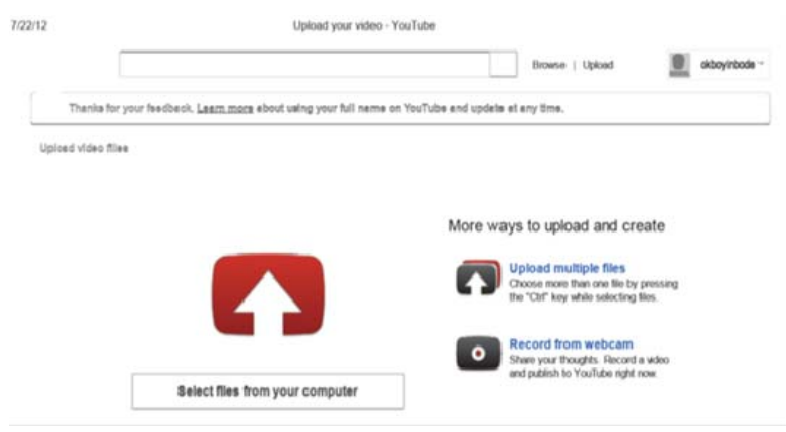

Figure 3. File Upload in YouTube

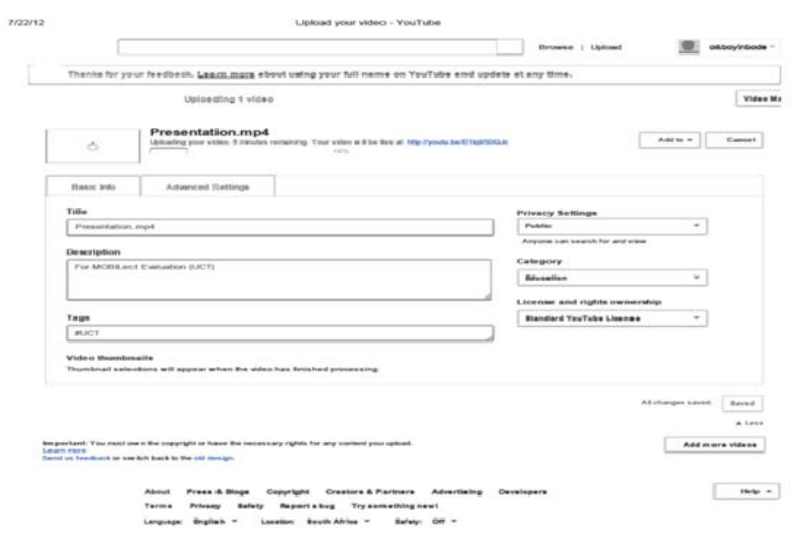

Figure 4. Details for File Upload in YouTube

\subsection{Architecture of MOBILect}

The proposed architecture (figure 5) describes the following components:

Mobile device:

- $\quad$ This provides interfacing for the user.
- This component displays and keeps images of videos and songs from the website.

- This device is updated when there is a post-back to query update for the application (application refresh). This uses data as it accessed a remote content provider (host website).

- The mobile device also provides store in the file system to store downloaded videos and audios.

- The mobile device stores the immediate threads that the user last viewed from the device in the application.

- The device sorts the videos searched according to the recently uploaded lectures.

- The interface is constantly updated in time intervals to update the data that is viewed on the application.

Host Web site:

- Provide the fields to access data for the application on the mobile device

- This has a database to store meta data for the data that was last gathered from the last mobile query (query).

- $\quad$ The host website will be updating the data store on any website access. With respect to the mock up design, it gives record of updated resources from various access points (comments from other users that use the host site). The host site also gives access to uploading new material to the site (media).

- The host website also categorizes the parts of the web site which will give a cascading interface to accessing the application as on the mock up design for the different design.

- Provide the view that the site can be viewed (mobile site, web site or web app)

Data storage:

- This basically stores all the activities on the host website.

- This stores the modification of data from the device (comments).

- It also keeps the meta-data for the updates to the site (administrator modifications).

- $\quad$ This stores the media files for the host site.

Administrator:

- Authorizes the components of the site that can be used remotely or by third parties. 
- Authorizes the database access and assign privileges on what access right another user can have to the data in the database.

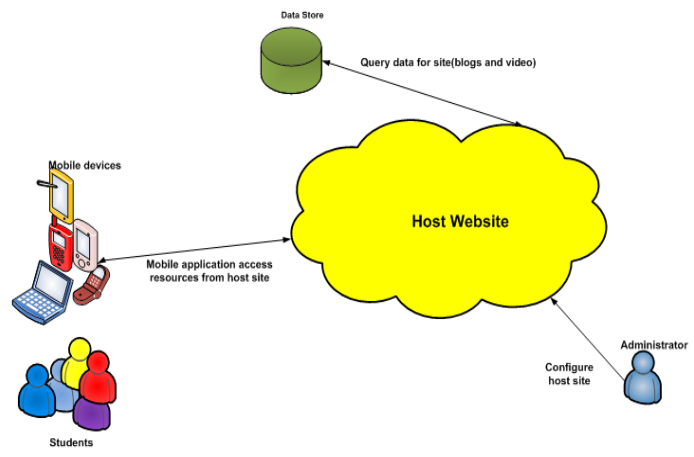

Figure 5. Architecture of an Interactive
Mobile Lecturing System

The architectural layers of the Mobile lecturing network (figure 6):

- Layer 1: describes the different types of mobile devices that can access the application;

- Layer 2: describes different operating systems that can run on the mobile devices;

- Layer 3: contain the access network through which the mobile devices can access the application;

- Layer 4: contain the Web-based HTML5 application (MOBILect). This does not require a middleware;

- Layer 5: describes the intended users of the application.

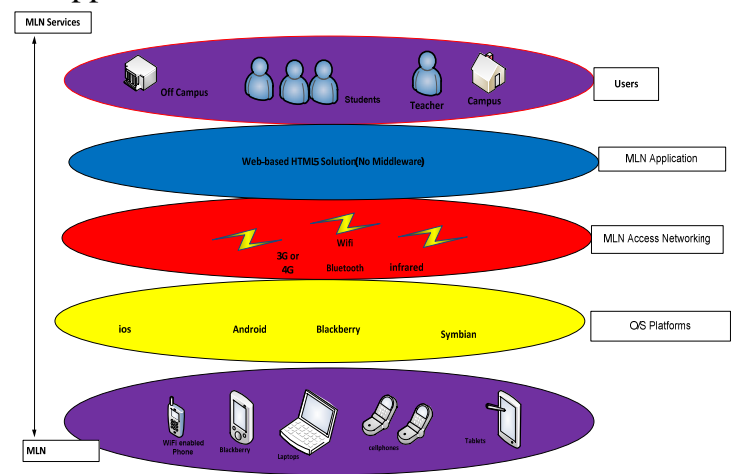

Figure 6. Architectural Layers of the Interactive Mobile Lecturing Network (MLN)

In Figure 7 MOBILect draws video files from YouTube at ttp://www.youtube.com/rss/tag/uct.rss. Video files are loaded into the MOBILect by uploading to YouTube using \# uct tag. Figure 7 shows some of the files that have been uploaded to YouTube using the \#uct tag.

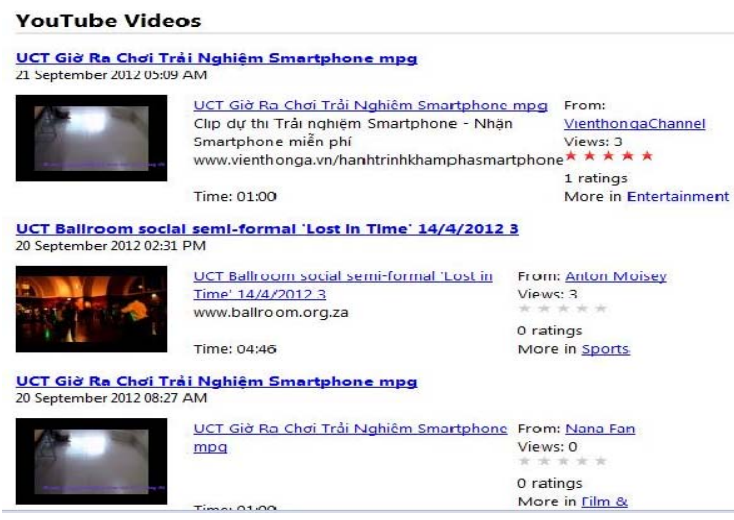

Figure 7. MOBILect draws files from YouTube

\section{Case Study}

Evaluation took place at Bindura University of Science Education, Zimbabwe to test MOBILect. The course evaluated was an Introduction to Computer Programming module (CS102) in the Department of Computer Science. The need for MOBILect at Bindura University and the computer science course stems from the parity between full time students and part-time students in the institution. Full-time students are always on campus throughout the year to receive instructions from teachers and sit for examination. The parttime students visit the campus only four times in a year to receive instructions and then sit for examinations with their full-time students' counterparts who had been steadily receiving instructions throughout the year. The part-time students are dispersed all over Zimbabwe and are employed hence engaged in part-time studies. They visit the campus only four times in a year to receive instructions. The consequence of this limitation is poor academic performance. MOBILect was adopted to assist these part-time students to interact with the lecture vodcast using their mobile devices on MOBILect to enhance their learning and performance (see Figure 8).

\subsection{Evaluation at Bindura University of Science Education}

For the purpose of evaluation at Bindura University of Science Education, Zimbabwe; Course 102 titled Introduction to Computer Programming was evaluated. Part time students were invited to use the MOBILect. Five students responded and evaluated MOBILect. The number of full time students enrolled for the course was 25 . The number of part-time students enrolled is 15 students. The lecture vodcast was recorded using Cam studio3 (see Figure 9). Cam Studio is open source software used to record the computer screen while including audio input. 


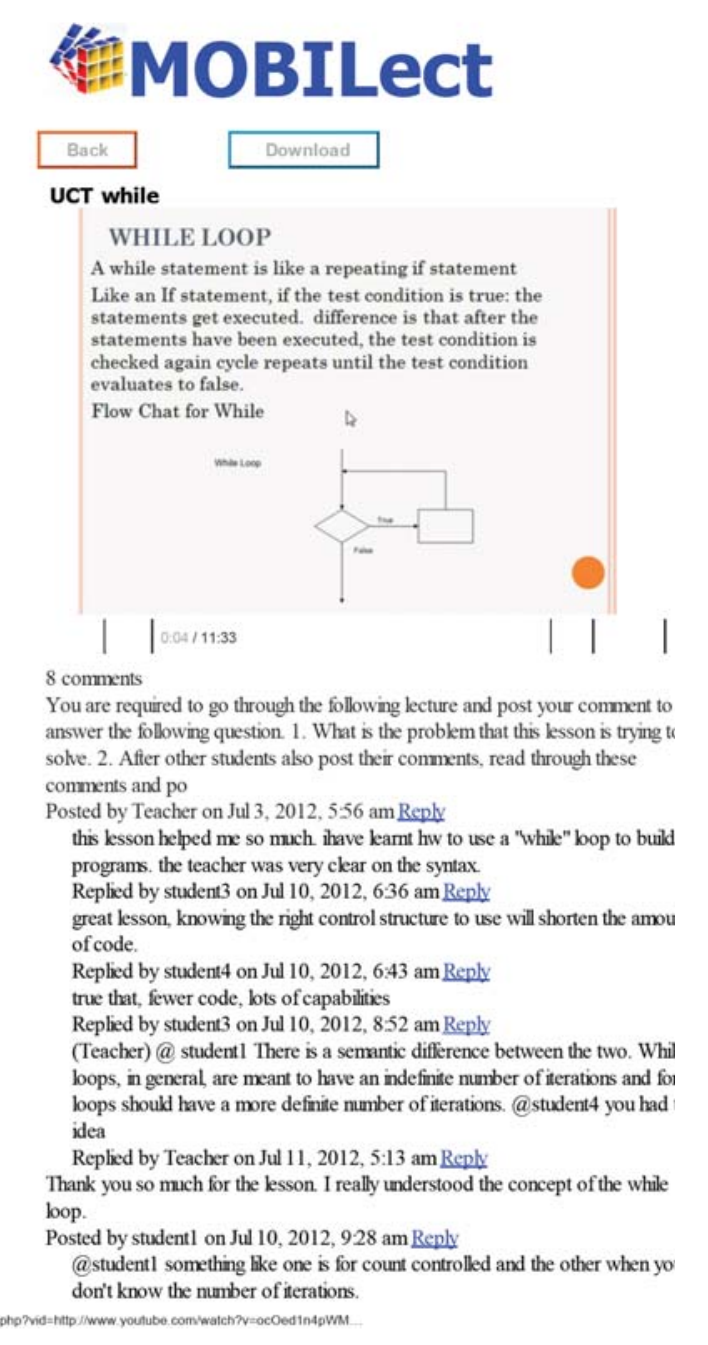

Figure 8. Evaluation using MOBILect

Cam Studio is capable of recording all screen activities that happen on the computer and the audio as well. Besides being an easy-to-use program, it has been designed with outstanding capabilities that enable it to record particular parts of the desktop indicated or the entire desktop. Once it has finished recording, Cam studio convert to SWF or AVI format. The lecture vodcast was loaded into MOBILect through YouTube integration. Five students evaluated MOBILect from different parts of Zimbabwe. The following devices were owned and used by the students to access MOBILect (see Figure 10 and 11): iPhone 3G, iPad, Blackberry curve 8520, Samsung Galaxy $\mathrm{S}$ and Sony Ericsson Xperia.

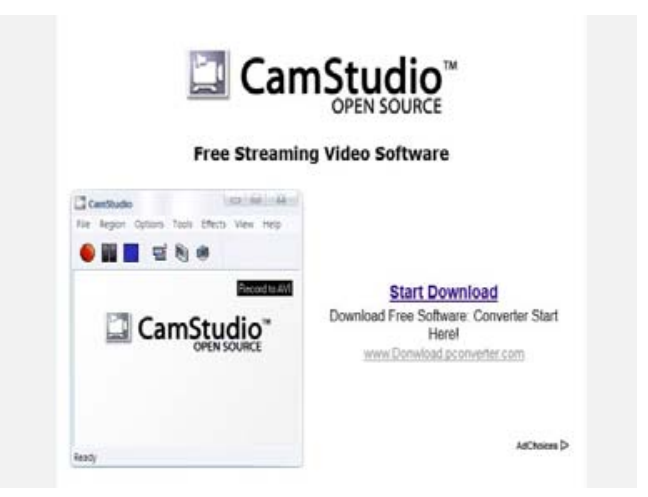

\section{Figure 9. CamStudio Source from www.camstudio.org}

\subsection{Analysis of Evaluation at Bindura University of Science Education, Zimbabwe}

In this evaluation based on the interactive mobile lecturing model in Figure 2; in the student-toteacher Interaction, teacher post question to interact and motivate the students. The question posted by teacher is "what is the problem that this lesson is trying to solve?" (See Figure 8). Explanation of the interactions is given in Table 1[2].

\section{Student-to-Content Interaction}

Posted by student\#3: This lesson helped me so much; I have learnt how to use a "while" loop to build programs. The teacher was very clear on the syntax.

Posted by student\#4: Great lesson, knowing the right control structure to use will shorten the amount of code

Posted by Student\#3: true that, fewer codes, lots of capabilities

Posted by Student \#2: The lesson makes it clear how a while loop is used comparing it with the if statement.

Posted by student\#1: So which one is the best loop to use between the two or under what circumstances can I use the while loop?

${ }^{2}$ Student-to-Student Interaction

Reply@student\#1: something like one is for count controlled and the other when you don't know the number of iterations. Posted by student4; Student4 replies student1

Posted by student\#1: Thank you so much for the lesson, I really understood the concept of the while loop

\footnotetext{
${ }^{2}$ www.camstudio.org
} 
Posted by Student\#5: I have not been posting comments on the platform but I have constantly viewed other people's comments and this has helped me much

\section{Student-to-Teacher Interaction:}

Reply@student\#1: There is a semantic difference between the two. While loops, in general, are meant to have an indefinite number of iterations and for loops should have a more definite number of iterations. Posted by by Teacher

Posted by Teacher: Hi all, your feedback shows that some have been able to grasp the concepts. From the example given, try to write a program that prints that numbers in reverse order.

Posted by Teacher: I can see that this platform enhances learning and helps others who do not always contribute on face to face to also contribute, the comments helped other students focus more on the most important concepts

Table1. Explanation of the Interactions

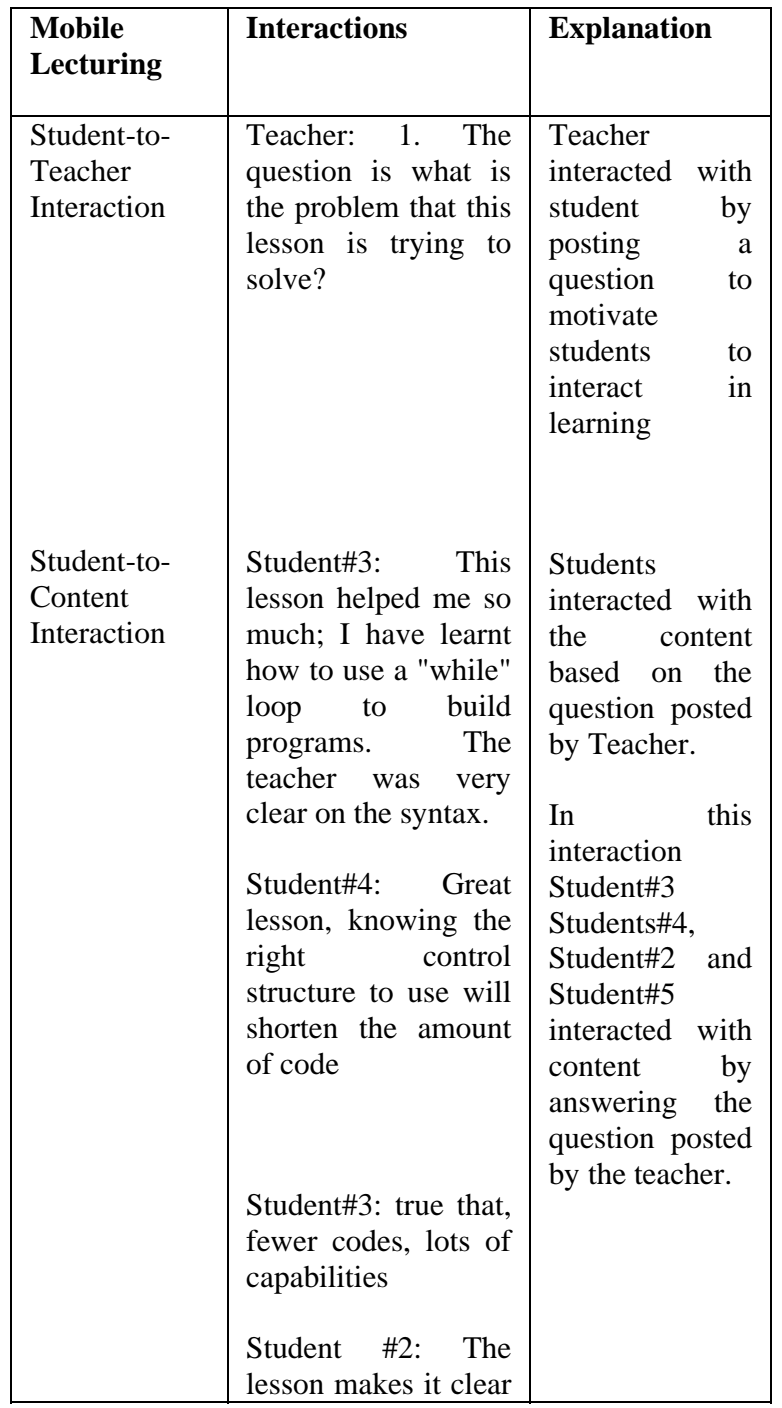

\begin{tabular}{|c|c|c|}
\hline $\begin{array}{l}\text { Student-to- } \\
\text { Student } \\
\text { Interaction }\end{array}$ & $\begin{array}{l}\text { how a while loop is } \\
\text { used comparing it } \\
\text { with the if statement. } \\
\text { Student\#5: I have } \\
\text { not been posting } \\
\text { comments on the } \\
\text { platform but I have } \\
\text { constantly viewed } \\
\text { other people's } \\
\text { comments and this } \\
\text { has helped me much } \\
\text { Posted by student\#1: } \\
\text { So which one is the } \\
\text { best loop to use } \\
\text { between the two or } \\
\text { under what } \\
\text { circumstances can I } \\
\text { use the while loop? } \\
\text { Reply@student\#1: } \\
\text { something like one } \\
\text { is for count } \\
\text { controlled and the } \\
\text { other when you don't } \\
\text { know the number of } \\
\text { iterations. Posted by } \\
\text { student4; } \\
\text { Posted by student\#1: } \\
\text { Thank you so much } \\
\text { for the lesson, I } \\
\text { really understood the } \\
\text { concept of the while } \\
\text { loop }\end{array}$ & $\begin{array}{l}\text { le } \\
\text { Student\#1 } \\
\text { responds } \\
\\
\\
\text { Here students } \\
\text { engaged in } \\
\text { high- level } \\
\text { interactions by } \\
\text { responding to } \\
\text { other students' } \\
\text { questions or } \\
\text { comments. This } \\
\text { interaction } \\
\text { exposes } \\
\text { students to } \\
\text { ideas and } \\
\text { concepts of } \\
\text { other students } \\
\text { hence } \\
\text { encouraging } \\
\text { deep learning }\end{array}$ \\
\hline $\begin{array}{l}\text { Student-to- } \\
\text { Teacher } \\
\text { Interaction }\end{array}$ & $\begin{array}{l}\text { Reply@student\#1: } \\
\text { There is a semantic } \\
\text { difference between } \\
\text { the two. While } \\
\text { loops, in general, are } \\
\text { meant to have an } \\
\text { indefinite number of } \\
\text { iterations and for } \\
\text { loops should have a } \\
\text { more definite } \\
\text { number of iterations. } \\
\text { Posted by Teacher } \\
\text { Posted by Teacher: }\end{array}$ & $\begin{array}{l}\text { Teacher replies } \\
\text { Student\#1 } \\
\text { question. }\end{array}$ \\
\hline
\end{tabular}




\begin{tabular}{|l|l|l|}
\hline Hi all, your feedback \\
shows that some \\
have been able to \\
grasp the concepts. \\
$\begin{array}{l}\text { From the example } \\
\text { given, try to write a } \\
\text { program that prints } \\
\text { that numbers in } \\
\text { reverse order. }\end{array}$ & $\begin{array}{l}\text { Teacher } \\
\text { comments on } \\
\text { the answers } \\
\text { posted by the } \\
\text { students This } \\
\text { interactions } \\
\text { with the teacher } \\
\text { encourages } \\
\text { Posted by Teacher: I } \\
\text { can see that this } \\
\text { platform enhances } \\
\text { learning and helps } \\
\text { others who do not } \\
\text { always contribute on } \\
\text { face to face to also } \\
\text { contribute, the } \\
\text { comments helped } \\
\text { other students focus } \\
\text { more on the most } \\
\text { important concepts }\end{array}$ \\
\hline
\end{tabular}

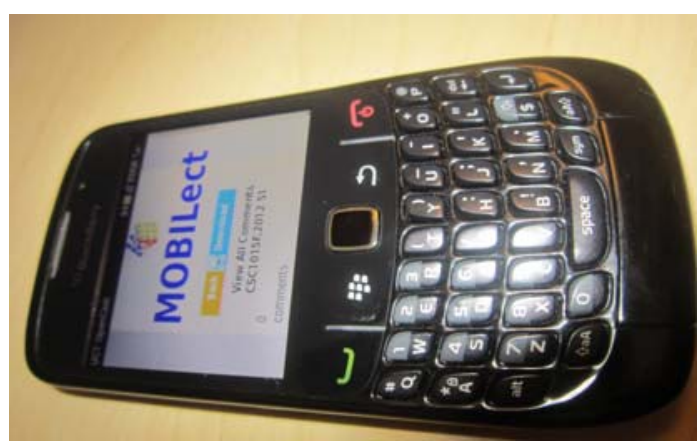

Figure 10. Blackberry Curve 8520

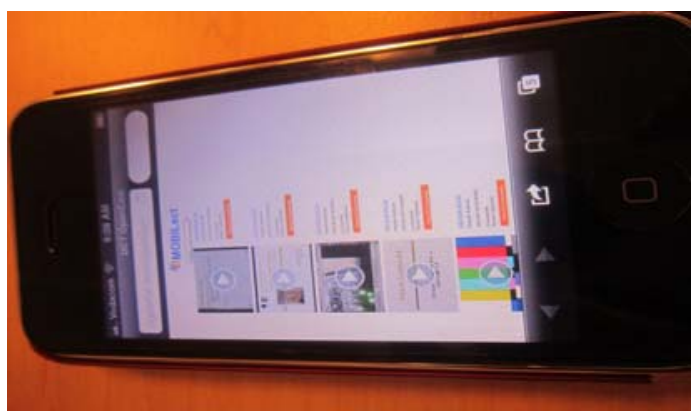

Figure 11. iPhone 3G

\section{Conclusion}

An Interactive Mobile Lecturing Tool "MOBILect was developed to enhance student engagement with face-to-face lectures using mobile lecturing interactions. Students interacted with lecture vodcasts on their mobile devices to foster deep learning. In this paper we have been able to implement MOBILect a mobile lecturing tool that enhances students' engagement with lecture vodcasts through mobile lecturing. This tool successfully ran on five different mobiles devices. MOBILect was successfully evaluated at Bindura University of Science Education, Zimbabwe. MOBILect is a good supplement to the traditional face-to-face lectures and can also be indispensable to higher education in other developing countries of Africa especially in scenarios where students are separated by distance.

\section{Acknowledgement}

We wish to acknowledge DAAD (the German Academic Exchange Service) and 2011 LOREALUNESCO Regional Fellowship for Women in Science in Sub-Saharan Africa, for their financial support to this research.

\section{References}

[1] Anderson, T. (2004). Toward a theory of online learning. In T. Anderson \& F. Elloumi (Eds.), Theory and practice of online learning (pp.33-60). Athabasca, AB: Athabasca University. Retrieved May 7, 2012, from http://cde.athabascau.ca/online_book/pdf/TPOL_chp02.p df

[2] Boyinbode, O. (2012). Towards a Mobile Lecturing Model: A Higher-Level Engagement for Enhancing Learning. Unpublished PhD Thesis, University of Cape Town, South Africa

[3] Copley, J. (2007). Audio and video podcasts for lectures for campus-based students' production and evaluation of student use. Innovations in Education and Teaching International, 44(4), 387-399

[4] Dyson, L. (2011). Does Going Mobile Always Make Learning Better? In T. Bastiaens \& M. Ebner (Eds.), Proceedings of World Conference on Educational Multimedia, Hypermedia and Telecommunications 2011 (pp. 2957-2966). Chesapeake, VA: AACE. Retrieved July 13, 2012 from http://www.editlib.org/p/38282

[5] Lee, M. J. W., \& Chan, A. (2007). Reducing the effects of isolation and promoting inclusivity for distance learners through podcasting. Online Submission, 8, 85105.

[6] Litchfield, A., Dyson, L. E., Lawrence, E., \& Zmijewska, A. (2007). Directions for m-learning research to enhance active learning. Proceedings Australasian Society for Computers in Learning in Tertiary Education (ASCLITE), Singapore 2007, pp. 587-596.

[7] Litchfield, A., Dyson, L. E., Wright, M., Pradhan, S., \& Courtille, B. (2010). Student-produced Vodcasts as Active Metacognitive Learning, 10th IEEE International Conference on Advanced Learning Technologies (ICALT), Sousse, Tunisia, 5-7th July, pp. 560-564.

[8] McGarr, O. (2009). A review of podcasting in higher education: Its influence on the traditional lecture. 
Australasian Journal of Educational Technology, 25(3), 309-321.

[9] Ng'ambi, D. (2008). Podcasts for Expansive Learning: A Case of Reflective Student Stories. South African Computer Journal: SACJ, 42, 9-14.

[10] Oliver, M., \& Luca, J. (2007). Using Mobile Technologies and Podcasts to Enhance Learning Experiences in Lecture-Based University Course Delivery. In C. Montagomerie and J. Seale (Eds.), Proceedings of Ed-Media World Conference on Educational Multimedia, Hypermedia and Telecommunications 2007, pp. 3385-3394.

[11] Warburton, K. (2003). 'Deep learning and education for sustainability’, International Journal of Sustainability in Higher Education 4(1), 44-56.

[12] Woukeu, A., Millard, D., Tao, F., \& Davis, H. (2005).Challenges for semantic grid-based mobile learning Proceedings for the IEEE SITIS Conference:http://www.u-ourgogne.fr/SITIS/

05/download/Proceedings/Files/f135.pdf retrieved 07 May 2012. 